\title{
Lessons from the Recovery Training Program for Service Users Empowerment
}

\author{
Marta Anczewska*, Alicja Multarzyńska, Joanna Krzyżanowska-Zbucka, Joanna Roszczyńska-Michta, \\ Justyna Waszkiewicz, Justyna Tucholska
}

First Psychiatric Department, Institute of Psychiatry and Neurology, Warsaw, Poland

Corresponding author: anczew@ipin.edu.pl

Received July 09, 2014; Revised July 18, 2014; Accepted August 17, 2014

\begin{abstract}
In the recent years there has been growing interest in the process of recovery, not in the sense of clinical remission but rather in terms of being able to lead a meaningful and satisfying life, despite illness symptoms and psychosocial difficulties. The personal recovery is driven by people's lived, subjective experiences of psychotic crisis and challenges the diagnosis of permanent, chronic, disabling mental illness. One of the activities, which might foster recovery, is lifelong learning paradigm. This paper presents the results of twelve hours training focused on the following topics: recovery - individual experiences, barriers in the process of recovery, social and internalized stigma, empowerment, personal strengths, problem solving, personal recovery plan, and life narrative story. The participants found it to be a positive experience: helpful and supportive. They agreed that talking of their strengths was much useful and made them feel good. In their opinions' the most important exercise was personal recovery plan which has given them the opportunity to establish individual, meaningful life goals, provide them with hope and self-determination. These results need replication and further work to identify what were the preconditions for making the training such a valuable experience and how this could be replicated on a wider basis.
\end{abstract}

Keywords: training, recovery, psychosis

Cite This Article: Marta Anczewska, Alicja Multarzyńska, Joanna Krzyżanowska-Zbucka, Joanna Roszczyńska-Michta, Justyna Waszkiewicz, and Justyna Tucholska, "Lessons from the Recovery Training Program for Service Users Empowerment.” American Journal of Educational Research, vol. 2, no. 9 (2014): 709712. doi: 10.12691/education-2-9-2.

\section{Introduction}

Mental illnesses, as far as the term exists, are connected with the great number of stereotypes, prejudice and social fears; they are ranked among the leading causes of disability worldwide [22,27]. Affected individuals suffer from self-stigma, diminished self-esteem and self-efficacy as a result $[6,8]$. Psychiatric hospitalization - even now oppressive, hierarchical system with lack of autonomy and intimacy changes individual's life perspective as traumatic experience.

The process of recovery applies to persons who live outside the mental illness. It has been identified as a multidimensional phenomenon consisting of clinical, existential, functional, physical and social dimensions $[5,9,10,11,24,28]$. It occurs through ongoing transactions between an individual and his or her world [12,20], as a continuing process of change which is not illness focused. Transaction in the process of recovery enhances a person's opportunities in gaining access to community-based resources and activities, helps to overcome barriers to social inclusion. The essence of recovery is defined by Davidson:

What recovery seems to entail is that people overcome the effects of being a mental patient - including the rejection from society, poverty, substandard housing, social isolation, unemployment, loss of valued social roles and identity, and loss of sense of self and purpose in lifein order to retain, or resume, some degree of control over their own lives. [[9], p. 38]

Ongoing debate about the recovery forms two groups of definitions which might be in tension with each other: service-based recovery and user-based recovery. The medical model drives the clinical view of the process recovery is understood to be a return to a former state of health. Outcomes include reduced symptoms, no psychiatric hospitalization and functional remission (involvement in work or school, independence on financial support from disability insurance, relations with friends). The personal view of recovery is driven by people's lived, subjective experiences of psychotic crisis and challenges the notion of permanent, chronic mental illness [17]. Outcomes include empowerment, hope, choice, self-defined goals, meaningful life, hopefulness and self-determination, healing, wellbeing and control of symptoms [1,5,24].

Traditional mental health services approach is illness focused, in which service user's role is to be subservient, passive, mainly responsible for following the treatment. The shift to recovery-oriented services means partnership and decision sharing: service user is considered to be an expert with unique experience - his or her role is based on 
personal power, knowledge and responsibility. Person in context of life is the focus and he / she is self-determining, as pointed out by Frak:

Recovery starts with the individual and works from the inside out. For this reason it is personalized and challenges traditional service approaches. [[14], p. 1]

The first-person accounts on recovery by Deegan, Goldowsky, however published many years ago, still form inspiring ideas for trainers, when structuring and running the recovery training program for service users' empowerment, indicating to focus on: acceptance of illness limitations and unpleasant flash-backs, growth out of: hopelessness, powerlessness, illness dominated sense of self and social inclusion:

Recovery is a process, a way of life, an attitude, and a way of approaching the day's challenges. It is not a perfectly linear process. At times our course is erratic and we falter, slide back, regroup and start again. The need is to meet the challenge of the disability and to re-establish a new and valued sense of integrity and purpose within and beyond the limits of the disability; the aspiration is to live, work, and love in a community in which one makes a significant contribution. [[13], p. 15]

My sociologist friend reminded me that we are not only mental patients; we are also writers, doctors, fishermen, husbands, wives, and children. For so many of us, mental problems are really just a fragment of our being. [[16], p. 823]

At a 2004 National Consensus Conference on Mental Health Recovery and Mental Health Systems Transformation organized by SAMHSA (The Substance Abuse and Mental Health Services Administration), patients, health care professionals and researchers agreed on ten core principles of recovery orientation: selfdirection, individualized and person-centered, strengthsbased, empowerment, respect, holistic, nonlinear, peersupport, responsibility and hope (http://www.apa.org/monitor/2012/01/recoveryprinciples.aspx).

The fundamental goals of the recovery: the reestablishment of normal roles in the community, the developments of a personal support network and an increased quality of life, might be achieved by lifelong learning paradigm and empowerment.

Lifelong learning is the development of human potential through a supportive process which stimulates and empowers individuals to acquire all the knowledge, skills, values and understanding they will need throughout their lifetimes and to apply them with confidence, creativity and enjoyment in all roles, circumstances and environments. [[19], p. 2]

Empowerment is now understood as a complex concept. It encompasses a number of phenomena relating to changing the social perception of mental disease, reforming the operations and rationale of medical care and social welfare, and changing the intra-psychic and behavioral dimensions of patients themselves. It combines both process and outcome.

\section{The Recovery Training Program}

\subsection{The Training Process and Structure}

The learning element of the training is based on learnercentered, team work on issues of common concerns to find solutions for diverse contexts. The workshop prioritizes a "three-fold concept" of competence development: developing sensitivity and awareness, knowledge and understanding, individual practice.

Theoretical background of the training is based on empowerment $[18,30]$ to learn how to gain control over one's own life; on personal recovery [1,5,7] how to acquire hopefulness and self-determination, rebuilt self-esteem and challenge the notion of permanent, chronic mental illness, on cognitive behavioral theory [3] how to fight self-stigma, on narrative theories [21,25,29] how to encouragingly analyze life experiences to establish new meaningful life goals, on illness identity [26] how to overcome the notion that mental illness means incompetence and powerlessness [15].

The twelve hours training is designed to be delivered by two psychologists and one psychiatrist in maximum ten persons group. The content of it was developed by a team of researchers with various professional backgrounds (a psychiatrist, two psychologists and an educator) with active input from service users, using a focus group strategy. The length and the structure of the training arrived as a result of evaluation made after the former training experience - in 2007 and 2008 the ten hours training "Empowering people in recovery" was run in the Institute of Psychiatry and Neurology in Warsaw, Poland [4].

The content of the training consists of the following topics [23]: recovery - individual experience, internalized stigma, empowerment, personal strengths, problem solving, personal recovery plan, life narrative story, with exercises: working out recovery definition, individual stop over recovery journey, barriers in recovery, personal values and strengths in opposition to stereotypes, respecting self and others boundaries, identity and social roles, situation-thought-emotion, what makes you feel strong?, being controlled and control others, personal recovery plan, how to manage the problem in regard psychotic crisis, my life is like "a book".

The idea of exploiting personal recovery plan as one of the training exercises, derived from Personal Development Plan (PDP) used in management and education to help people to clarify what and when to change. The trainees were asked the following questions to be answered as their written homework: what are your motives and defenses that run your life, what it is you want to change or improve in your life, what are the resources that will be helpful to making those changes, what are your fundamental life challenges that block your ability to succeed, what gives you meaning and purpose, what are the values that bring you strength, what are your goals in the long terms, what are your goals in the short terms, what are the stages of achieving these goals, how do you know you are successful, what is in future on the way to personal recovery, what is in past on the way to personal recovery, please schedule a specific amount of time to pursuit your personal recovery plan, please take notes on what you are learning.

Each teaching session lasts two hours with fifteen minutes break, taught over six weeks, organized in the afternoon in order to not interfere with participants daily duties. People are provided with educational materials to 
make homework which is discussed in the group during subsequent session. After the module is concluded the participants anonymously evaluate the program in regards content, structure and trainers skills.

\subsection{Participants}

Service users were contacted through clinical services in the Institute of Psychiatry and Neurology in Warsaw, Poland. The announcement titled "Recovery Workshops" was put on the Institute official web side with general training information, a contact person and a telephone number. The decision to participate in the training was strictly voluntary. Inclusion criteria were as follows: aged 18 and over, suffering from schizophrenia or delusional disorders. We decided to train schizophrenia or delusional disorders sufferers since these illnesses are ranked among the leading causes of disability worldwide [22].

The subsequent workshops were run within 24 months (from October 2011 till October 2013). The trainers noticed that the participants usually dropped out from the last training session. It might be explained as a form of "overstimulation" and should be taken into consideration when planning the next intervention structure.

\subsection{Results}

70 service users concluded the training. Participants age varied from 20 to 50 years, the women were in majority (67\%), as well as people with higher education (61\%), unemployed (71\%), and using mental health services not longer than five years (56\%).

In general the service users' opinions on recovery represent four dimensions: satisfaction of life- e.g. recovery means better living, accomplish life goals, coping with life challenges; well-being- e.g. recovery it is soma and psyche balance; recovery means accept myselfmy failures; social support- e.g. recovery means having close friends; to recover is to have friendly people around and supportive family; personhood - e.g. recovery means to be a person not a case, to acknowledge that mental illness has no relation to me as a person. These opinions support the notion of personal recovery rather than medical one. Among all the participants there was no single opinion on illness symptoms reduction, medication use or employment in terms of recovery.

The trainees' recommendations were in accordance with Personal Assistance in Community Existence A recovery guide [2]: recovery beliefs - e.g. it is useful to think of the future instead of the past unpleasant experiences; recovery relationships - e.g. a person should have supportive friends and trust in God, it is helpful to talk with people with the same experience; recovery skills - e.g. a person should found new goals, it is helpful to know that everyone may fail and should forgive himself; recovery identity - e.g. think of you as a husband not a psychiatric patient. The participants didn't refer to recovery community, namely work or helping others.

All of the participants, who took part in the sessions showed full engagement with the training, however not all of them did homework completely and carefully. They underlined that exercise on their strengths was much helpful and made them feel good. In their opinions' the most useful exercise was individual recovery plan: every participant got feedback in a form of positive "reformulation" in the process which was active not passive.

The exercise has given the trainees the opportunity to establish individual, meaningful life goals, provide them with hope and self-determination.

The trainers observed positive dynamic of the group during the training sessions - team work was built up, leaders appeared, group shared friendliness and openness.

Authors' training experience supports the ongoing debate about the two groups of recovery definitions: service-based recovery and user-based recovery. Among all the participants of the training there was no single opinion on service-based recovery namely illness symptoms reduction, medication use or employment. They focused on dimensions of personal recovery: life satisfaction, well-being, social support, and personhood. The participants didn't also refer to recovery community, this can be explained by organizational factors - there are hardly any recovery-promoting initiatives in Polish mental health system.

There is no single definition for the recovery. It is suggested that this is because recovery is a journey shaped by an individual's own experiences and stages. The twelve hours training focused on the principles of recovery orientation was positively judged by service users suffering from schizophrenia and delusional disorders they found it helpful and supportive.

These results need replication and further work to identify what were the preconditions for making the training such a valuable experience and how this could be replicated on a wider basis.

\section{References}

[1] Adame, A.L., Knudson, R.M. "Recovery and the good life: how psychiatric survivors are provisioning the healing process", Journal of Humanistic Psychology, 48 (2), 142-164, 2008.

[2] Ahern, L. and Fisher, D. "Personal Assistance in Community Existence A recovery guide, Recovery at your own PACE", National Empowerment Center, Inc., 1999, Available: http://www.power2u.org/

[3] Alford, B.A., and Beck, A.T. The Integrative Power of Cognitive Therapy, Guilford New York 1997.

[4] Anczewska M. and Ryan P. "Lifelong learning and recovery: an account from the perspective of the EMILIA project”, Occasional Papers in Education and Lifelong Learning an International Journal, 3, 59-68, 2009.

[5] Andresen, R., Oades, L., Caputi, P. Psychological recovery: beyond mental illness, Wiley-Blackwell 2011.

[6] Brohan, E., Elgie, R., Sartorius, N., Thornicroft, G. "Self-stigma, empowerment and perceived discrimination among people with schizophrenia in 14 European countries: the GAMIAN-Europe study”, Schizophrenia Research, 122 (1-3), 232-238, 2010.

[7] Cohen, C. "How do we recover? An analysis of psychiatric survivor oral histories”, Journal of Humanistic Psychology, 45 (3), 333-354, 2005.

[8] Corrigan, P.W., Watson, A.C. "The paradox of self-stigma and mental Illness”, Clinical Psychology: Science and Practice, 9 (1), 35-53, 2002.

[9] Davidson, L. Living outside mental illness: Qualitative studies of recovery in schizophrenia, New York: New York University Press, 2003.

[10] Davidson, L., Borg, M., Marin, I., Topor, A., Mezzina, R., Sells, D. "Processes of recovery in serious mental illness: findings from a multinational study", American Journal of Psychiatric Rehabilitation, 8, 177-201, 2005a.

[11] Davidson, L., O’Connell, M.J., Tondora, J., Lawless, M., Evans, A.C. "Recovery in serious mental illness: a new wine or just a new 
bottle?” Professional Psychology: Research and Practice 36 (5), 480-487, 2005b.

[12] Davidson, L. "Habits and other anchors of everyday life that people with psychiatric disabilities may not take for granted", OTJR: Occupation, Participation and Health, 27 (4), S60-S68, 2007.

[13] Deegan, P.E. "Recovery: the lived experience of rehabilitation", Psychosocial Rehabilitation Journal, 11 (4), 11-19, 1988.

[14] Frak D. "Recovery Learning: A Report on the Work of the Recovery Learning Sites and other Recovery-Orientated Activities and its Incorporation into "The Rethink Plan 2004-08". Rethink, 2005

[15] Glover, H. Recovery, lifelong learning, empowerment and social inclusion: is a new paradigm emerging? Empowerment, Lifelong Learning and Recovery in Mental Health Towards a New Paradigm, ed. Peter Ryan, Shulamit Ramon and Tim Greacen, Palgrave Macmillan, 15-35, 2012.

[16] Goldowsky, M. "On confronting myself and the world", Psychiatric Services, 54, 823-824, 2003.

[17] Leamy, M. Bird, C., Le Boutillier, J. Williams, M. "Conceptual framework for personal recovery in mental health: systematic review and narrative synthesis”, British Journal of Psychiatry, 199 (6), 445-452, 2011

[18] Linhorst, D.M., Eckert, A. "Conditions for empowering people with severe mental illness”, Social Service Review, 6, 279-304, 2003.

[19] Longworth, N. Making lifelong learning work: learning cities for a learning century, Routledge, Taylor \& Francis Group 1999.

[20] Onken, S.J., Craig, C.M., Ridgeway, P., Ralph, R. and Cook, J. "An analysis of the definitions and elements of recovery: A review of the literature”, Psychiatric Rehabilitation Journal, 31, 9-22, 2007.

[21] Pennebaker, J.W., Seagal, J.D. "Forming a story: the health benefits of narrative”, Journal of Clinical Psychology, 55(10), 1243-1254, 1999.

[22] Prince, M., Patel, V., Saxena, S., Maj, M., Maselko, J., Phillips, M.R., Rahman, A. "No health without mental health", The Lancet, 370 (9590), 859-877, 2007.

[23] Roszczyńska-Michta J. Anczewska M., Waszkiewicz J. Zdrowienie-budowanie własnej narracji, Instytut Psychiatrii i Neurologii, Warszawa, 2009.

[24] Schrank, B., Slade, M. "Recovery in psychiatry", Psychiatric Bulletin, 31, 321-325, 2007.

[25] Thornhill, H., Clark, L., May, R. "Escape, enlightenment and endurance Narratives of recovery from psychosis”, Anthropology and Medicine, 11 (2), 181-199, 2004.

[26] Yanos, P.T., Roe, D., Lysaker, P.H. “The impact of illness identity on recovery from severe mental illness", American Journal of Psychiatric Rehabilitation, 13 (2), 73-93, 2010.

[27] World Health Organization "World report on disability 2011", Available: http://www.who.int/disabilities/world_report/2011/report.pdf.

[28] Whitley, R., Drake, R.E. "Recovery: a dimensional approach”, Psychiatric Services 61 (12), 1248-1250, 2010.

[29] Wisdom, J.P., Bruce, K., Saedi, G.A., Weis, T., Green, C.A "Stealing me from myself": identity and recovery in personal accounts of mental illness", Australian and New Zealand Journal of Psychiatry, 42, 489-495, 2008.

[30] Zimmerman, M.A. "Psychological empowerment: issues and illustrations”, American Journal of Community Psychology, 23 (5) 581-599, 1995. 